\title{
CENTRO DE ESTUDOS FRANCO DA ROCHA
}

PRESIDENTE: DR. DARCY MENDONÇA UCHOA

Sessão ordinária - 24 outubro 1944.

Inicialmente, foi empossada a diretoria eleita para reger a Sociedade durante 1945, composta dos Drs. Darcy Mendonça Uchoa (presidente), José P. G. d'Alambert (secretário) e Paulo Simioni (tesoureiro). 
Assistência psiquiátrica no Brasil. Prof. Adauto Botelho (convidado).

$\mathrm{O}$ autor referiu-se ao papel que deve representar o psiquiatra moderno; fèz um apanhado sôbre a evolução da psiquiatria, focalizando o estado atual da Assistência Psiquiátrica no Brasil. Utilizando dados estatísticos, mostrou o que já se fêz, principalmente no Rio de Janeiro, em São Paulo e em Recife, e o que ainda resta, a fazer. Pôs em evidência a necessidade de aumentar o número de leitos para os alienados, analisou a situação, nesse setor, de cada Estado da União, em seus recursos, em altas concedidas e em óbitos registrados; fêz um apanhado sôbre a incidência regional de certas doenças mentais, acentuou a necessidade de uma organização hospitalar perfeita com todos os recursos modernos, apresentou as vantagens da escola de enfermagem especializada e, por fim, frisou que o aperfeiçoamento médico-psiquiátrico se faz necessário para resolver de maneira completa o problema da doença mental que cada vez se torna mais assustador.

\section{Sessão ordinária - 22 novembro 1944}

Epilepsia pós-convulsoterápica. Dr. Luis Cerqueira (convidado).

O autor refere o caso de uma mulher de 34 anos, branca, filha de pai psicopata, apresentando um quadro esquizof rênico desde março de 1943, com remissões pela convulsoterapia, seguidas de recidivas. Depois de 14 aplicações de cardiazol e 48 eletrochoques, o eletrencefalograma revelava disritmia generalizada, pelo que foi suspensa a convulsoterapia, sabido que estados epilépticos espontâneos podent-se instalar em $0,5 \%$ de casos submetidos à convulsoterapia, explicados por um mecanismo já esboçado pela escola peruana de Delgado e Trelles, como resultantc da integração cortical que tem o ataque epiléptico no sêr humano. Posteriormente, a paciente apresentou realmente crises espontâneas, mas antes disso foi leucotomizada em vista de persistirem os sintomas de esquizofrenia. Se bem que já se tenham observado convulsões após lobotomia, o autor sente-se inclinado a ligar as convulsões apresentadas pela doente a um estado criado pela convulsoterapia e sugerido pelo eletrencefalograma. A leucotomia parece ter tido um papel secundário.

Reportando-se a seus estudos e aos de Sal y Rosas, sôbre a cronometria do acesso cardiazólico, o autor lembra que, após 15-30 choques, a duração total aumenta de muito, o que significaria possivelmente a instalação de um estado ictafim, representando a série até 20 choques, aquela que se pode considerar sem nenhuin dano para o sistema nervoso, impondo-se daí por diante uma verificação eletrencefalográfica caso seja necessário prosseguir o tratamento.

\section{Sessão ordinária - 20 dezembro 1944.} bortella.

Síndromo psiquiatrico do lobo frontal. Drs. Anibal Silveira e Mario Ro-

Em resumo, os sintomas psíquicos do paciente apresentado são: orienta-se quanto a si próprio, mas não no meio exterior; apesar de reconhecer-se doente, revela completa indiferença pela própria situação; falta de iniciativa para pensar, falar e agir ; cada vez que efetua algum esfôrço muscular (levantar-se, andar, sentar-se, vestir-se) cantarola ou assobia ao mesmo tempo. Como sinais neurológicos há ataxia, desordens da marcha de tipo frontal, vivacidade de reflexos tendinosos, perturbações da visão e convulsões epileptiformes. $O$ exame do liqüido céfalo-raquidiano não revelou alterações. Foi feito diagnóstico de lesão do lobo frontal na camada profunda da região. $O$ diagnóstico topográfico foi confirmádo pelo exame pneumencefalográfico.

Considerações sôbre o Congresso de Neurologia e Psiquiatria de Buenos Aires. Dr. Mario Yahn. 
$O$ autor informou à casa os principais acontecimentos relacionados com o Congresso realizado em Buenos Aires em comemoração ao $25 .^{\circ}$ aniversário da Sociedade de Neurologia e Psiquiatria da Associação Médica Argentina. A comissão paulista era composta pelos Drs. Edgard Pinto Cesar, Mario Yahn, Oyntho Mattos e Sylvio Griecco. Aderiram à representação o Dr. Orestes Barini, coms representante da Fôrça Policial do Estado e o Dr. Bierrenbach de Castro, cm nome da Sociedade de Medicina de Campinas. O Dr. Olavo Neri representou o Serviço de Neurologia da Universidade do Rio de Janeiro.

$\mathrm{O}$ congresso realizou-se em ambeinte de grande cordialidade e os temas foram debatidos com o propósito de registrar os progressos alcançados pelos diversos ramos da especialidade nos últimos anos. Assim é que ficou patenteado o avanço da neurocirurgia, a contribuição moderna para o esclarecimento do problema da esilepsia e da esquizofrenia cujo estudo prognóstico foi um dos temas principais. Notável é o desenvolvimento da psicanálise no meio sul-americano, o que se deve, scm dúvida, aos trabalhos da escola psicanalítica, fundada recentemente em Buenos Aires.

\section{Sessão ordinária - 22 janeiro 1945.}

Sentimento de inferioridade física condicionando desvios de caráter. Dr. Pa ılo Lentino.

O A. apresentou um caso adleriano de uma paciente portadora de defeito físico (paralisia infantil) que, devido à inferioridade física, apresentou um desvio de caráter, chegando mesmo a um estado psicopático.

\section{Sessão extraordinária - 7 fevereiro 1945.}

Esta reunião extraordinária foi dedicada à memória de Vicente Batista. O Dr. Cândido da Silva proferiu um discurso, referindo-se às atividades de Vicente Batsita como médico, principalmente na Pediatria e dentro da Assistencia a Psicopatas de São Paulo, pondo em relêvo sua obra científica, composta de 126 trabalhos, entre os quais uma monografia premiada pela Academia Nacional de Medicina.

\section{Sessão ordinária - 20 fevcrciro 19:5}

Sôbre um caso de melancolia ansiosa. Dr. Henrique Mendes.

Tratava-se de uma mulher cujos distúrbios psíquicos datando de 4 anos, cessaram após leucotomia, intervenção praticada após o fracasso de outros processos terapêuticos. A paciente, com 63 apos de idade, era portadora de um quadro de melancolia ansiosa. desencadeado logo após o falecimento de uma filha; julgava que havia descuidado do trato da mesma, atormentando-se com êsse pensamento; tôda sua ideação, mímica e gesticulação, todo seu psiquismo emfim, era polarizado e dominado por intensos sentimentos de culpa estritamente confinados, monótonos, fixos, sempre se traduzindo pelas mesmas expressões verbais, as mesmas exclamações de dor, a mesma ansiedade, a mesma inquietação mctora. Os tratamentos de choque (cardiazol, insulina, eletrochoque) resultaram pràticamente negativos. Foi submetida à leucotomia a Egas Moniz, em janeiro de 1945, tendo sido operada pelo Dr. A. C. Barretto, decorrendo o ato operatório sem incidentes. O tempo de observação ainda é relativamente curto, 23 dias, mas o resultado imediato foi o de remissão completa, mostrando-se a paciente calma c sossegada, criticando com certa precisão seu passado e reconhecendo a morbides de suas reações emocionais. $\mathrm{O} A$. reconhece a necessidade de maior tempo de observação para se poder avaliar devidamente a profundidade da remissão obtida. 
Psicocirurgia: selę̧̃o e reeducą̧ão dos doentes. Dr. . C. Barretto.

Historiando a evolução da cura das doentes mentais pela cirurgia, mostra o autor o quanto é antiga essa terapêutica, que sòmente com a leucotonia préfrontal de Egaz Muniz, em 1935, voltou a ser focalizada sob novas bases. Referese aos trabalhos de Walter Freeman e James Watts que, em 1936, propuzeram, a lobotomia pré-frontal. Faz referência às várias técnicas de Moniz, Fræeman, Lyerly e Crombie. Estuda a questão da seleção dos doentes, mostrando sua importância e, também, a divergência existente entre os autores no que se rcfere à indicação cirúrgica; os entusiastas do método propõem como primeiro tratamento psiquiátrico a cirurgia extensaé os moderados, mais restritos na indicação psicocirúrgica, a propõem como tratamento final, após o fracasso de outras tentativas terapêuticas.

Reporta-se, depois, aos resultados que já obteve na esquizofrenia, na psicose maniaco-depressiva, na psicose de intvolução, nas personalidades psicopáticas e na epilepsia psíquica cuja estatística é boa e parece confirmar a indicação terapêutica. Salienta, finalmente, a necessidade de cuidados pós-operatórios, encarecendo c papel da enfermagem especializada na reeducação dos doentes submetidos a psicocirurgia. 